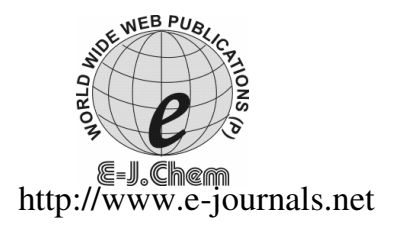

ISSN: 0973-4945; CODEN ECJHAO

E-Journal of Chemistry

2011, 8(1), 9-18

\title{
Adsorption of Malachite Green Dye by Acid Activated Carbon - Kinetic, Thermodynamic and Equilibrium Studies
}

\author{
P. K. BASKARAN, B. R VENKATRAMAN ${ }^{\S}$ and S ARIVOLI* \\ Department of Chemistry \\ Government Arts College, Dharmapuri-636705, India \\ ${ }^{\S}$ P.G \& Research Department of Chemistry \\ Periyar E V R College (Autonomous), Thiruchirapalli-620 023, India \\ Department of Chemistry \\ *Thiru. Vi. Ka. Government College, Thiruvarur-610 003, India \\ arivu3636@yahoo.com
}

Received 6 June 2010; Revised 18 August 2010; Accepted 1 September 2010

\begin{abstract}
The ability of zea mays dust carbon to remove malachite green from aqueous solutions has been studied for different adsorbate concentrations by varying the amount of adsorbent, temperature, $\mathrm{pH}$ and shaking time. Thermodynamic parameters such as $\Delta \mathrm{H}^{\circ}, \Delta \mathrm{S}^{\circ}$ and $\Delta \mathrm{G}^{\circ}$, were calculated from the slope and intercept of the linear plots. Analysis of adsorption results obtained at $303,313,323$ and $333 \mathrm{~K}$ showed that the adsorption pattern on zea mays dust carbon seems to follow the Langmuir and Freundlich. The numerical values of sorption free energy indicate physical adsorption. The kinetic data indicated an intra-particle diffusion process with sorption being first order. The concentration of malachite green oxalate was measured before and after adsorption by using UV-visible spectrophotometer.
\end{abstract}

\section{Introduction}

Malachite green is highly cytotoxic to mammalian cells and also acts as a liver tumorenhancing agent. The concentration and effective utilization of activated carbon generated from natural plant material have attracted worldwide attention in a view of the large disposal problem without detriment to environment. Many investigators have studied the feasibility of using inexpensive alternative materials like pearl millet husk, date pits, saw dust, buffing dust of leather industry, coir pith, crude oil residue, tropical grass, olive stone and almond shells, pine bark, wool waste, coconut shell etc., as carbonaceous precursors for the removal of dyes from water and wastewater ${ }^{1-3}$. 
The present study undertaken to evaluate the efficiency of a carbon adsorbent prepared from acid activated zea mays dust carbon for the removal of malachite green dye in aqueous solution. In order to design adsorption treatment systems, knowledge of kinetic and mass transfer processes is essential. In this paper, the applicability of kinetic and mass-transfer models for the adsorption of malachite green onto acid activated carbon is reported.

\section{Experimental}

The dried zea mays dust was carbonized with concentrated sulphuric acid in the weight ratio of $1: 1(\mathrm{w} / \mathrm{v})$. Heating for twelve hours in a furnace at $500{ }^{\circ} \mathrm{C}$ has completed the carbonization and activation. The resulting carbon was washed with distilled water until a constant $\mathrm{pH}$ of the slurry was reached. Then the carbon was dried for four hours at $100{ }^{\circ} \mathrm{C}$ in a hot air oven. The dried material was ground well to a fine powder and sieved.

\section{Adsorption dynamic experiments}

\section{Batch equilibration method}

The adsorption experiments were carried out in a batch process at $30,40,50$ and $60{ }^{\circ} \mathrm{C}$ temperatures. The known weight of adsorbent material was added to $50 \mathrm{~mL}$ of the dye solutions with an initial concentration of $10 \mathrm{mg} / \mathrm{L}$ to $50 \mathrm{mg} / \mathrm{L}$. The contents were shaken thoroughly using a mechanical shaker rotating with a speed of $120 \mathrm{rpm}$. The solution was then filtered at preset time intervals and the residual dye concentration was measured.

\section{Effect of variable parameters}

\section{Dosage of adsorbent}

The various doses of the adsorbents are mixed with the dye solutions and the mixture was agitated in a mechanical shaker. The adsorption capacities for different doses were determined at definite time intervals by keeping all other factors constant.

\section{Initial concentration of dye}

In order to determine the rate of adsorption, experiments were conducted with different initial concentrations of dyes ranging from 10 to $50 \mathrm{mg} / \mathrm{L}$. All other factors were kept constant.

\section{Contact time}

The effect of period of contact on the removal of the dye on adsorbent in a single cycle was determined by keeping particle size, initial concentration, dosage, $\mathrm{pH}$ and concentration of other ions constant.

\section{Initial $p H$}

Adsorption experiments were carried out at $\mathrm{pH} 2,3,4,5,6,7,8,9$ and 10. The acidic and alkaline $\mathrm{pH}$ of the media was maintained by adding the required amounts of dilute hydrochloric acid and sodium hydroxide solutions. The parameters like particle size of the adsorbents, dye concentration, dosage of the adsorbent and concentration of other ions are kept constant while carrying out the experiments. The $\mathrm{pH}$ of the samples was determined using a portable $\mathrm{pH}$ meter, Systronics make. The $\mathrm{pH}$ meter was calibrated with 4.0 and 9.2 buffers.

\section{Chloride}

The experiments were done in the presence of varying chloride environments using various sodium chloride solutions. While doing the experiments, the absence of other anions was ensured. 


\section{Temperature}

The adsorption experiments were performed at four different temperatures viz., 30, 40, 50 and $60{ }^{\circ} \mathrm{C}$ in a thermostat attached with a shaker, Remi make. The constancy of the temperature was maintained with an accuracy of $\pm 0.5^{\circ} \mathrm{C}$.

\section{Zero point charge}

The $\mathrm{pH}$ at the potential of zero charge of the carbon $\left(\mathrm{pH}_{\mathrm{zpc}}\right)$ was measured using the $\mathrm{pH}$ drift method $^{4,5}$. The $\mathrm{pH}$ of the solution was adjusted by using $0.01 \mathrm{M}$ sodium hydroxide or hydrochloric acid. Nitrogen was bubbled through the solution at $25{ }^{0} \mathrm{C}$ to remove the dissolved carbon dioxide. $25 \mathrm{mg}$ of the activated carbon was added to $50 \mathrm{~mL}$ of the solution. After stabilization, the final $\mathrm{pH}$ was recorded. The graphs of final $\mathrm{pH}$ versus initial $\mathrm{pH}$ used to determine the zero point charge of the activated carbon.

\section{Desorption studies}

Desorption studies help to elucidate the nature of adsorption and recycling of the spent adsorbent and the dye. The effect of various reagents used for desorption were studied.

\section{Results and Discussion}

\section{Characterization of the adsorbent}

Activated carbons are a widely used adsorbent due to its high adsorption capacity, high surface area, micro porous structure and high degree of surface respectively. The wide usefulness of carbon is a result of their specific surface area, high chemical and mechanical stability. The chemical nature and pore structure usually determines the sorption activity. The physicochemical properties are listed in Table 1.

Table 1. Characteristics of the adsorbent

\begin{tabular}{lc}
\hline \multicolumn{1}{c}{ Properties } & ZDC \\
\hline Particle size, mm & 0.042 \\
Density, g/cc & 0.3253 \\
Moisture content, \% & 1.75 \\
Loss on ignition, \% & 92 \\
Acid insoluble matter, \% & 2.10 \\
Water-soluble matter, \% & 0.48 \\
$\mathrm{pH}_{\text {of aqueous solution }}$ & 6.85 \\
$\mathrm{pH}_{\text {zpc }}$ & 6.25 \\
\hline
\end{tabular}

\section{Effect of contact time and initial dye concentration}

The experimental results of adsorptions of at various concentrations (10 to $50 \mathrm{mg} / \mathrm{L})$ with contact time are shown in representative Figure 1 . The equilibrium data were collected in Table 2 reveals that, percent adsorption decreased with increase in initial dye concentration, but the actual amount of dye adsorbed per unit mass of carbon increased with increase in dye concentration. It means that the adsorption is highly dependent on initial concentration of dye. It is because of that at lower concentration, the ratio of the initial number of dye molecules to the available surface area is low subsequently the fractional adsorption becomes independent of initial concentration. However, at high concentration the available sites of adsorption becomes fewer and hence the percentage removal of dye is dependent upon initial concentration ${ }^{5,6}$ Equilibrium have established at 40 minutes for all concentrations. Figure 1 reveals that the curves are single, smooth, and continuous, leading to saturation, suggesting the possible monolayer coverage of the dyes on the carbon surface. 


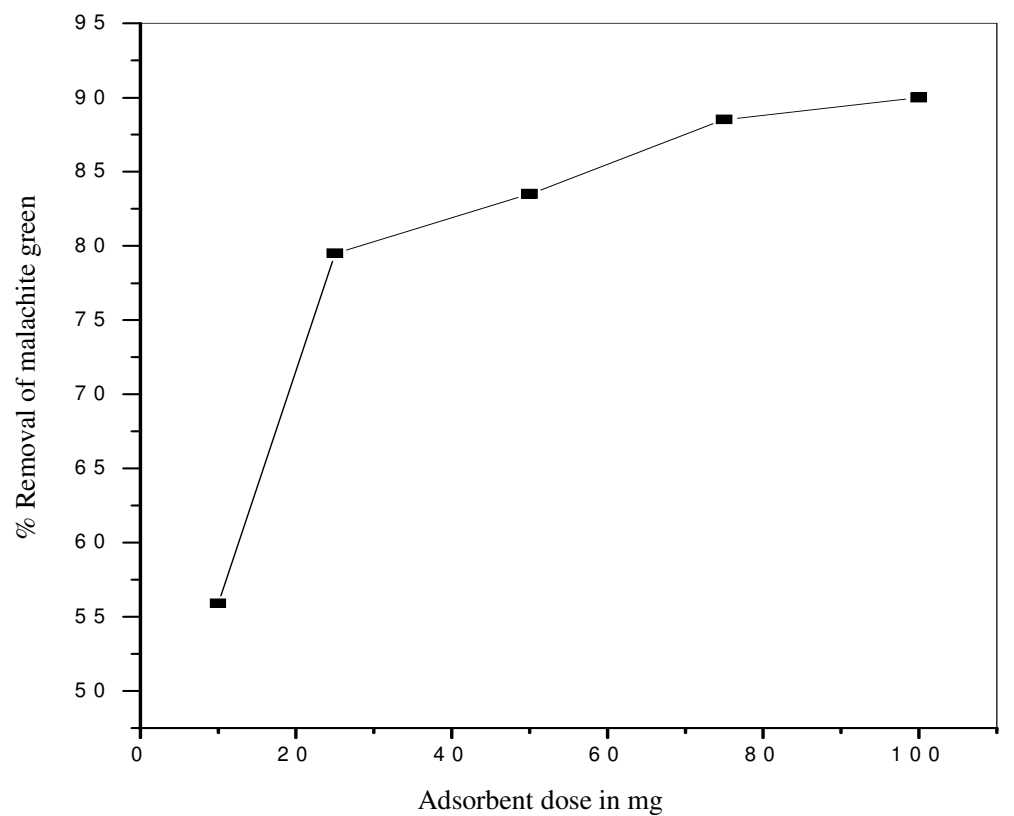

Figure 1. Effect of adsorbent dose on the removal of malachite green $[\mathrm{M}]=30 \mathrm{mg} / \mathrm{L}$; contact time $=60 \mathrm{~min} ;$ temp $=35^{\circ} \mathrm{C}$

Table 2. Equilibrium parameters for the adsorption of malachite green onto activated carbon

\begin{tabular}{cccccccccccccccc}
\hline \multirow{2}{*}[\mathrm{MG}]{$_{0}$} & \multicolumn{4}{c}{$\mathrm{C}_{\mathrm{e}}, \mathrm{mg} / \mathrm{L}$} & \multicolumn{4}{c}{$\mathrm{Q}_{\mathrm{e}}, \mathrm{mg} / \mathrm{g}$} & \multicolumn{4}{c}{ Dye removed, \% } \\
\cline { 2 - 13 } & $30^{\circ} \mathrm{C}$ & $40^{\circ} \mathrm{C}$ & $50^{\circ} \mathrm{C}$ & $60^{\circ} \mathrm{C}$ & $30^{\circ} \mathrm{C}$ & $40^{\circ} \mathrm{C}$ & $50^{\circ} \mathrm{C}$ & $60^{\circ} \mathrm{C}$ & $30^{\circ} \mathrm{C}$ & $40^{\circ} \mathrm{C}$ & $50^{\circ} \mathrm{C}$ & $60^{\circ} \mathrm{C}$ \\
\hline 10 & 1.1415 & 0.8402 & 0.6505 & 0.5015 & 17.7170 & 18.3196 & 18.6990 & 18.9970 & 88.58 & 91.59 & 93.49 & 94.98 \\
20 & 3.1545 & 2.9162 & 2.7092 & 2.5156 & 33.6910 & 34.1676 & 34.5816 & 34.9688 & 84.22 & 85.41 & 86.45 & 87.42 \\
30 & 6.0415 & 5.8012 & 5.6015 & 5.4012 & 47.9170 & 48.3976 & 48.797 & 49.1976 & 79.86 & 80.66 & 81.32 & 81.99 \\
40 & 10.1814 & 9.6146 & 9.1177 & 8.6185 & 59.6372 & 60.7708 & 61.7646 & 62.7630 & 74.54 & 75.96 & 77.20 & 78.45 \\
50 & 15.6056 & 14.7165 & 13.8189 & 12.9950 & 68.7888 & 70.5670 & 72.3622 & 74.0100 & 68.78 & 70.56 & 72.36 & 74.01 \\
\hline
\end{tabular}

\section{Effect of carbon concentration}

The adsorption of the malachite green dye on carbon was studied by varying the carbon concentration $(10-250 \mathrm{mg} / 50 \mathrm{~mL})$ for $30 \mathrm{mg} / \mathrm{L}$ of dye concentration. The percent adsorption increased with increase in the carbon concentration (Figure 2). This was attributed to increased carbon surface area and availability of more adsorption sites ${ }^{6}$. Hence the entire studies are carried out with the adsorbent dose of $25 \mathrm{mg}$ of adsorbent $150 \mathrm{~mL}$ of the adsorbate solution.

\section{Adsorption isotherm}

Figure 3 shows the Langmuir adsorption ${ }^{7}$ isotherms of the dye at 303, 313, 323 and $333 \mathrm{~K}$ using the zea mays dust carbon. The Langmuir equation assumes that there is no interaction between the sorbate molecules and that the sorption is localized in a monolayer. It is then assumed that once a dye molecule occupies a site, no further sorption can take place at that site. Theoretically, therefore, a saturation value is reached; beyond which no further sorption can take place. Compared to the Langmuir isotherm, the Freundlich ${ }^{8}$ model is generally found to be better suited for characterizing multi-layer adsorption process. 


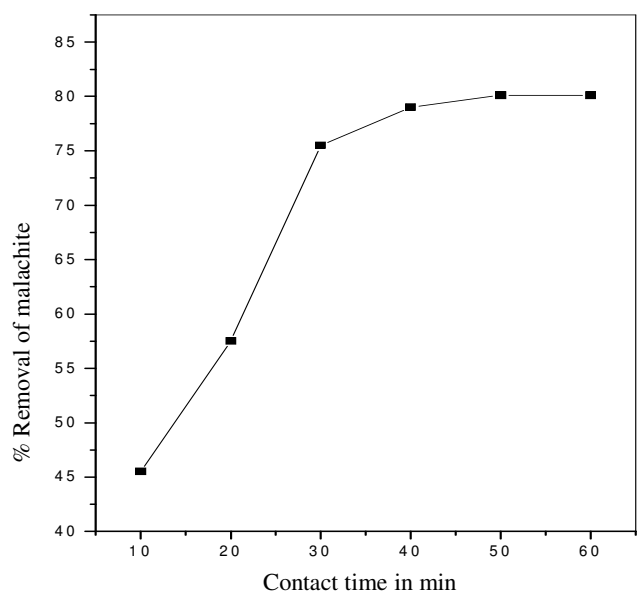

Figure 2. Effect of contact time on the removal of malachite green $[\mathrm{M} \mathrm{G}]=30 \mathrm{mg} / \mathrm{L}$; adsorbent dose $=25 \mathrm{mg} / 50 \mathrm{~mL}$; temp $=30^{\circ} \mathrm{C}$

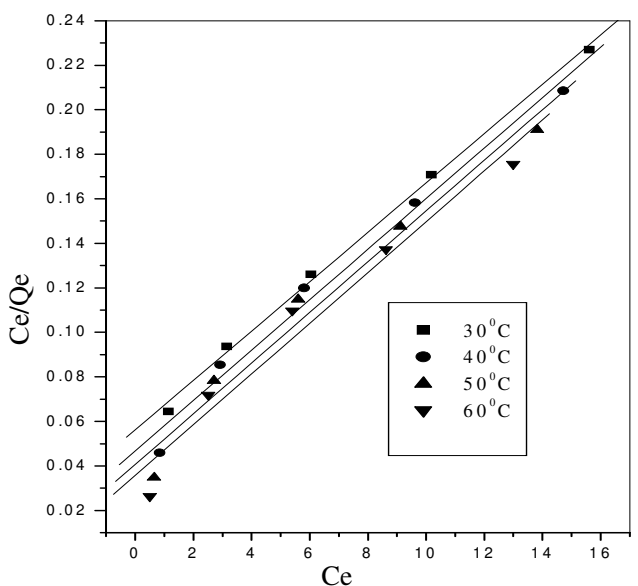

Figure 3. Linear Langumir isotherm for the adsorption of malachite green onto ZDC

The Langmuir parameters, $\mathrm{Q}_{\mathrm{m}}$ and ' $\mathrm{b}$ ' were computed from the slopes and intercepts of the straight lines of plot of $\left(\mathrm{C}_{\mathrm{e}} / \mathrm{Q}_{\mathrm{e}}\right) v s . \mathrm{C}_{\mathrm{e}}$ (Figure 3), while the values of Freundlich constants, i.e. $\mathrm{K}_{\mathrm{f}}$ and $1 / \mathrm{n}$ were calculated from the plots (Figure 4) of $\log \mathrm{C}_{\mathrm{e}}$ against $\log \mathrm{Q}_{\mathrm{e}} \cdot \mathrm{Q}_{\mathrm{m}}$ and ' $\mathrm{b}$ ' are Langmuir constants related to absorption capacity and energy of adsorption, respectively, while $\mathrm{K}_{\mathrm{f}}$ indicates the adsorption capacity and $1 / \mathrm{n}$ is indicative of the intensity of reaction ${ }^{9-11}$ Parameters of the Langmuir and Freundlich isotherms are computed in Table 3 and 4, the essential characteristics of a Langmuir constant separation factor or equilibrium parameter, $\mathrm{R}_{\mathrm{L}}$,

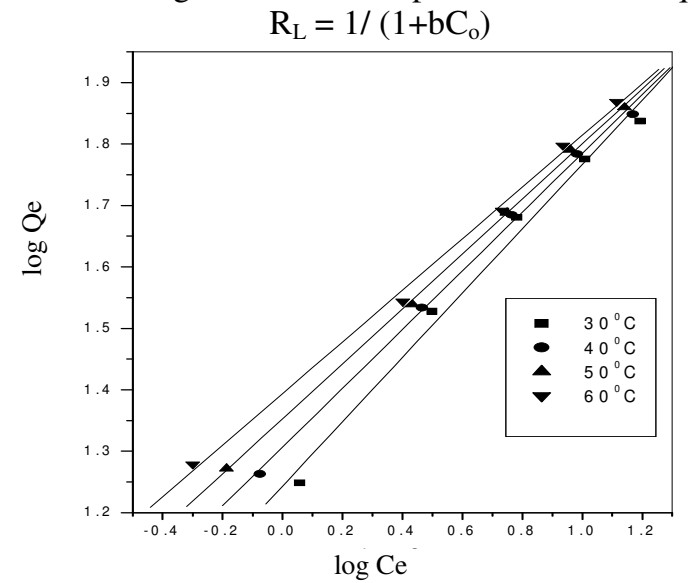

Figure 4. Linear Freundlich isotherm for the adsorbent of malachite green onto SDC

Table 3. Langmuir isotherm results

\begin{tabular}{ccccc}
\hline \multirow{2}{*}{ Dye } & Temp & \multicolumn{3}{c}{ Statistical parameters/constants } \\
\cline { 2 - 5 } & ${ }^{0} \mathrm{C}$ & $\mathrm{r}^{2}$ & $\mathrm{Q}_{\mathrm{m}}$ & b \\
\hline \multirow{2}{*}{ MG } & 30 & 0.9965 & 90.09 & 0.1972 \\
& 40 & 0.9969 & 88.49 & 0.2421 \\
& 50 & 0.9967 & 87.72 & 0.2801 \\
& 60 & 0.9990 & 86.95 & 0.3225 \\
\hline
\end{tabular}


Table 4. Freundlich isotherm results

\begin{tabular}{ccccc}
\hline Dye & Temp & \multicolumn{3}{c}{ Statistical parameters/constants } \\
\hline \multirow{3}{*}{ MG } & ${ }^{0} \mathrm{C}$ & $\mathrm{r}^{2}$ & $\mathrm{~K}_{\mathrm{f}}$ & $\mathrm{n}$ \\
& 30 & 0.9923 & 3.4670 & 1.9094 \\
& 40 & 0.9853 & 3.6947 & 2.0916 \\
& 50 & 0.9838 & 3.8678 & 2.2326 \\
& 60 & 0.9797 & 4.0305 & 2.3792 \\
\hline
\end{tabular}

Where ' $b$ ' is Langmuir constant and $C_{e}$ is the initial concentration of the dye ${ }^{12,13}$ The value of $\mathrm{R}_{\mathrm{L}}$ calculated from the above expression shown in Table 5 lies in the range of 0 to 1 , indicates favourable adsorption of malachite green oxalate on zea mays dust carbon for all studied concentrations at $303,313,323$ and $333 \mathrm{~K}$.)

Table 5. Dimensionless separation factor $\left(\mathrm{R}_{\mathrm{L}}\right)$

\begin{tabular}{ccccc}
\hline & \multicolumn{4}{c}{ Temperature, ${ }^{0} \mathrm{C}$} \\
\cline { 2 - 5 } $\begin{array}{c}\mathrm{MG}]_{0} \\
\mathrm{mg} / \mathrm{L}\end{array}$ & 30 & 40 & 50 & 60 \\
\hline 10 & 0.336 & 0.292 & 0.236 & 0.236 \\
20 & 0.202 & 0.171 & 0.151 & 0.134 \\
30 & 0.144 & 0.121 & 0.106 & 0.093 \\
40 & 0.112 & 0.093 & 0.081 & 0.072 \\
50 & 0.092 & 0.076 & 0.066 & 0.058 \\
\hline
\end{tabular}

\section{Effect of temperature}

The adsorption capacity of the carbon increased with increase in the temperature of the system from $30^{\circ}-60{ }^{\circ} \mathrm{C}$. Thermodynamic parameters such as change in free energy $\left(\Delta \mathrm{G}^{\circ}\right)(\mathrm{kJ} / \mathrm{mol})$, enthalpy $\left(\Delta \mathrm{H}^{\circ}\right)(\mathrm{kJ} / \mathrm{mol})$ and entropy $\left(\Delta \mathrm{S}^{\circ}\right)(\mathrm{J} / \mathrm{K} / \mathrm{mol})$ were determined using the following equations

$$
\begin{gathered}
\mathrm{K}_{0}=\mathrm{C}_{\text {solid }} / \mathrm{C}_{\text {liquid }} \\
\Delta \mathrm{G}^{\circ}=-\mathrm{RT} \ln \mathrm{K}_{\mathrm{O}} \\
\log \mathrm{K}_{0}=\Delta \mathrm{S}^{\circ} /(2.303 \mathrm{RT})-\Delta \mathrm{H}^{\circ} /(2.303 \mathrm{RT})
\end{gathered}
$$

Where $\mathrm{K}_{\mathrm{o}}$ is the equilibrium constant, $\mathrm{C}_{\mathrm{solid}}$ is the solid phase concentration at equilibrium $(\mathrm{mg} / \mathrm{L}), \mathrm{C}_{\text {liquid }}$ is the liquid phase concentration at equilibrium $(\mathrm{mg} / \mathrm{L}), \mathrm{T}$ is the temperature in Kelvin and $\mathrm{R}$ is the gas constant. The $\Delta \mathrm{H}^{\circ}$ and $\Delta \mathrm{S}^{\circ}$ values obtained from the slope and intercept of van't Hoff plots have presented in Table 6. The values of $\Delta \mathrm{H}^{\circ}$ and $\Delta \mathrm{S}^{\circ}$ and $\Delta \mathrm{G}^{\circ}$ were calculated as previously. Positive values of $\Delta \mathrm{H}^{\circ}$ and $\Delta \mathrm{S}^{\circ}$ suggest endothermic reaction, while the negative values of free energy change $\left(\Delta \mathrm{G}^{\circ}\right)$ indicate that the adsorption is spontaneous (Table 6) .The positive values of $\Delta S^{\circ}$ suggest the increased randomness at the solid-solution interface during desorption of malachite green oxalate on zea mays dust carbon. In desorption of the dye, the adsorbed solvent molecules, which are displaced by the adsorbate species, gain more translational entropy than is lost by the adsorbate ions, thus allowing for the prevalence of randomness in the system ${ }^{12,13}$.

Table 6. Equilibrium constant and thermodynamic parameters for the adsorption of malachite green onto activated carbon

\begin{tabular}{ccccccccccc}
\hline & \multicolumn{9}{c}{$\mathrm{K}_{0}$} & \multicolumn{9}{c}{$\Delta \mathrm{G}^{\mathrm{o}}$} & & $\Delta \mathrm{H}^{\mathrm{o}}$ & $\Delta \mathrm{S}^{\mathrm{o}}$ \\
\cline { 2 - 11 }$[\mathrm{MG}]_{0}$ & \multicolumn{9}{c}{ Temperature, ${ }^{\circ} \mathrm{C}$} \\
\cline { 2 - 11 } & $30^{\circ}$ & $40^{\circ}$ & $50^{\circ}$ & $60^{\circ}$ & $30^{\circ}$ & $40^{\circ}$ & $50^{\circ}$ & $60^{\circ}$ & & \\
\hline 10 & 7.760 & 10.901 & 14.372 & 18.940 & -5161 & -6216 & -7157 & -8143 & 54.79 & 198.93 \\
20 & 5.340 & 5.858 & 6.382 & 6.950 & -4220 & -4600 & -4977 & -5367 & 7.35 & 38.18 \\
30 & 3.965 & 4.171 & 4.355 & 4.554 & -3470 & -3716 & -3951 & -4197 & 3.84 & 24.15 \\
40 & 2.928 & 3.160 & 3.387 & 3.641 & -2706 & -2994 & -3276 & -3577 & 6.05 & 29.92 \\
50 & 2.203 & 2.397 & 2.618 & 2.847 & -1990 & -2275 & -2584 & -2897 & 7.18 & 30.25 \\
\hline
\end{tabular}




\section{Kinetics of adsorption}

The kinetics of sorption describes the solute uptake rate, which in turn governs residence time or sorption reaction. It is one of the important characteristics in defining the efficiency or sorption. In the present study, the kinetics of the dye removal was carried out to understand the behaviour of these low cost carbon adsorbents. The adsorption of malachite green dye from an aqueous follows reversible first order kinetics, when a single species are considered on a heterogeneous surface. The heterogeneous equilibrium between the dye solutions and the activated carbon are expressed as

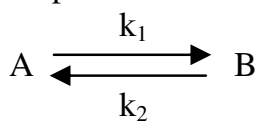

Where $\mathrm{k}_{1}$ is the forward rate constant and $\mathrm{k}_{2}$ is the backward rate constant. A represents dye remaining in the aqueous solution and $\mathrm{B}$ represent dye adsorbed on the surface of activated carbon. The equilibrium constant $\left(\mathrm{K}_{0}\right)$ is the ration of the concentration adsorbate in adsorbent and in aqueous solution $\left(\mathrm{K}_{0}=\mathrm{k}_{1} / \mathrm{k}_{2}\right)$.In order to study the kinetics of the adsorption process under consideration the following kinetic equation proposed by Natarajan and Khalaf as cited in literature has been employed ${ }^{13}$.

$$
\log \mathrm{C}_{0} / \mathrm{C}_{\mathrm{t}}=\left(\mathrm{K}_{\mathrm{ad}} / 2.303\right) \mathrm{t}
$$

Where $\mathrm{C}_{0}$ and $\mathrm{C}_{\mathrm{t}}$ are the concentration of the dye in (in $\mathrm{mg} / \mathrm{L}$ ) at time zero and at time $\mathrm{t}$, respectively. The rate constants $\left(\mathrm{K}_{\mathrm{ad}}\right)$ for the adsorption processes have been calculated from the slope of the linear plots of $\log \mathrm{C}_{0} / \mathrm{C}_{\mathrm{t}}$ versus ' $\mathrm{t}$ ' for different concentrations and temperatures. The determination of rate constants as described in literature given by

$$
\mathrm{K}_{\mathrm{ad}}=\mathrm{k}_{1}+\mathrm{k}_{2}=\mathrm{k} 1+\left(\mathrm{k}_{1} / \mathrm{K}_{0}\right)=\mathrm{k}_{1}\left[1+1 / \mathrm{K}_{0}\right]
$$

The overall rate constant $\mathrm{k}_{\mathrm{ad}}$ for the adsorption of dye at different temperatures are calculated from the slopes of the linear Natarajan-Khalaf plots. The rate constant values are collected in Table 7 shows that the rate constant $\left(\mathrm{k}_{\mathrm{ad}}\right)$ increases with increase in temperature suggesting that the adsorption process in endothermic in nature. Further, $\mathrm{k}_{\mathrm{ad}}$ values decrease with increase in initial concentration of the dye. In cases of strict surface adsorption a variation of rate should be proportional to the first power of concentration. However, when pore diffusion limits the adsorption process, the relationship between initial dye concentration and rate of reaction will not be linear. Thus, in the present study pore diffusion limits the overall rate of dye adsorption. The over all rate of adsorption is separated into the rate of forward and reverse reactions using the above equation. The rate constants for the forward and reverse processes are also collected in Table 7 indicate that, at all initial concentrations and temperatures, the forward rate constant is much higher than the reverse rate constant suggesting that the rate of adsorption is clearly dominant ${ }^{13}$.

Table 7. Rate constants for the adsorption of malachite green dye $\left(10^{3} \mathrm{k}_{\mathrm{ad}}, \mathrm{min}^{-1}\right)$ and the constants for forward $\left(10^{3} \mathrm{k}_{1}, \mathrm{~min}^{-1}\right)$ and reverse $\left(10^{3} \mathrm{k}_{2}, \mathrm{~min}^{-1}\right)$ process

\begin{tabular}{cccccccccccccc}
\hline & \multicolumn{10}{c}{ Temperature, ${ }^{0} \mathrm{C}$} \\
{$[\mathrm{D}]_{0}$} & \multicolumn{10}{c}{$\mathrm{k}_{\mathrm{ad}}$} & \multicolumn{10}{c}{30} & \multicolumn{3}{c}{50} & \multicolumn{2}{c}{60} \\
\cline { 2 - 15 } & $30^{\circ}$ & $40^{\circ}$ & $50^{\circ}$ & $60^{\circ}$ & $\mathrm{k}_{1}$ & $\mathrm{~K}_{2}$ & $\mathrm{k}_{1}$ & $\mathrm{k}_{2}$ & $\mathrm{k}_{1}$ & $\mathrm{k}_{2}$ & $\mathrm{k}_{1}$ & $\mathrm{k}_{2}$ \\
\hline 10 & 28.33 & 34.14 & 35.46 & 46.33 & 2.50 & 3.23 & 31.27 & 2.86 & 33.15 & 2.30 & 44.01 & 2.32 \\
20 & 22.42 & 23.71 & 25.34 & 29.36 & 18.89 & 3.53 & 20.25 & 3.45 & 21.90 & 3.43 & 25.66 & 3.69 \\
30 & 18.48 & 16.42 & 19.68 & 20.31 & 14.76 & 3.72 & 13.24 & 3.15 & 16.00 & 3.67 & 16.66 & 3.65 \\
40 & 15.46 & 14.61 & 16.81 & 17.14 & 11.53 & 3.93 & 11.10 & 3.51 & 12.98 & 3.83 & 13.45 & 3.69 \\
50 & 13.16 & 13.81 & 14.50 & 16.58 & 9.05 & 4.10 & 9.75 & 4.06 & 10.49 & 4.01 & 12.27 & 4.31 \\
\hline
\end{tabular}




\section{Intra-particle diffusion}

The most commonly used technique for identifying the mechanism involved in the sorption process is by fitting the experimental data in an intraparticle diffusion plot. Previous studies by various researchers showed that the plot of Qt versus $\mathrm{t}^{0.5}$ represents multi linearity, which characterizes the two or more steps involved in the sorption process. According to Weber and Morris ${ }^{14}$, an intraparticle diffusion coefficient $\mathrm{K}_{\mathrm{p}}$ is defined by the equation:

$$
\mathrm{K}_{\mathrm{p}}=\mathrm{Q} / \mathrm{t}^{0.5}
$$

Thus the $\mathrm{K}_{\mathrm{p}}\left(\mathrm{mg} / \mathrm{g} \min ^{0.5}\right)$ value can be obtained from the slope of the plot of $\mathrm{Qt}(\mathrm{mg} / \mathrm{g})$ versus $\mathrm{t}^{0.5}$ for malachite green (Figure 5), it was noted that the sorption process tends to be followed by two phases. The two phases in the intraparticle diffusion plot suggest that the sorption process proceeds by surface sorption and intraparticle diffusion ${ }^{14,15}$. The initial curved portion of the plot indicates a boundary layer effect while the second linear portion is due to intraparticle or pore diffusion. The slope of the second linear portion of the plot has been defined as the intraparticle diffusion parameter $\mathrm{K}_{\mathrm{p}}\left(\mathrm{mg} / \mathrm{g} \mathrm{min}^{0.5}\right)$. On the other hand, the intercept of the plot reflects the boundary layer effect. The larger the intercept, the greater the contribution of the surface sorption in the rate limiting step. The calculated intra-particle diffusion coefficient $\mathrm{K}_{\mathrm{p}}$ value was given by $0.285,0.324,0.358,0.393$ and $0.424 \mathrm{mg} / \mathrm{g} \mathrm{min}{ }^{0.5}$ for initial dye concentration of 10 to $50 \mathrm{mg} / \mathrm{L}$ at $30{ }^{\circ} \mathrm{C}$.

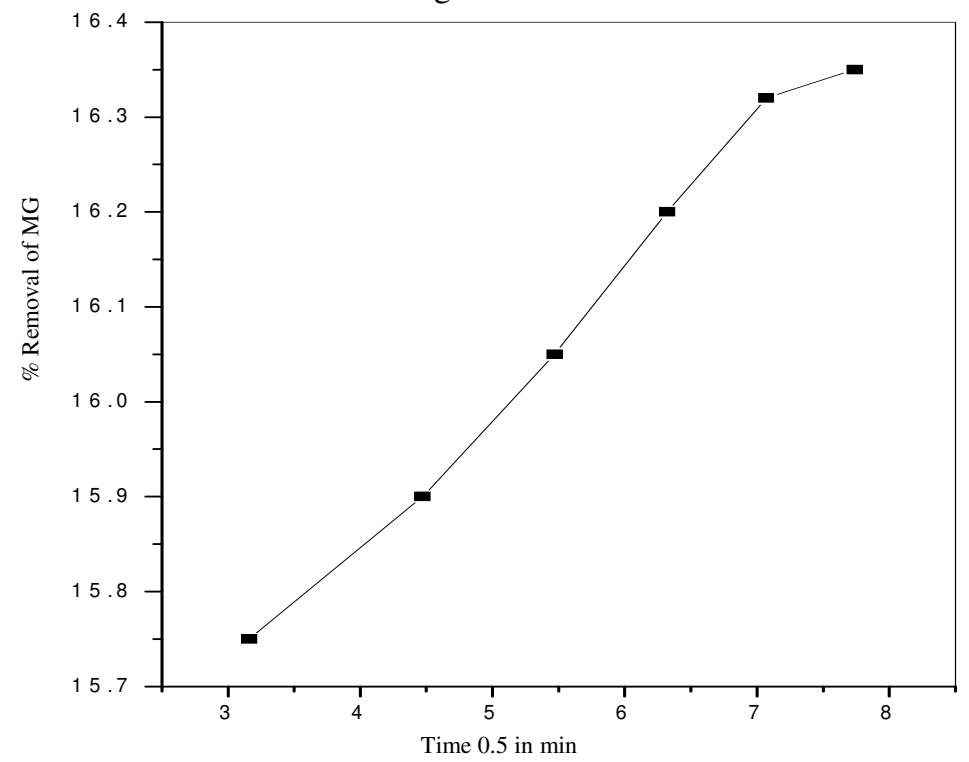

Figure 5. Intra-particle diffusion effect the adsorption of malachite green $[\mathrm{M} \mathrm{G}]=30 \mathrm{mg}$./L; temp $=30{ }^{\circ} \mathrm{C}$; contact time $=60 \mathrm{~min}$; adsorbent dose $=25 \mathrm{mg} / 50 \mathrm{~mL}$

\section{Effect of $p H$}

The influence of $\mathrm{pH}$ on the dye adsorption onto zea mays dust carbon was studied while the dye concentration, shaking time and amount of adsorbent were fixed. The variation of malachite green adsorption on zea mays dust carbon over a $\mathrm{pH}$ range of $3.0-9.0$ is shown in Figure 6. The result reveals that the adsorption of the dye increases from $45 \%$ to $93 \%$ with an increase in $\mathrm{pH}$ of the solution from 3.0 to 9.0 and then remains almost constant. 
The adsorption of these charged dye groups onto the adsorbent surface is primarily influenced by the surface charge on the adsorbent, which is in turn influenced by the solution $\mathrm{pH}$. The $\mathrm{pH}_{\mathrm{zpc}}$ value for zea mays dust carbon was 6.25 . At $\mathrm{pH}$ values below $\mathrm{pH}_{\mathrm{zpc}}$ the adsorbent had net positive charge and would, therefore, be prone to electro statically repel cation. Malachite green is a cationic basic dye as denoted by the presence of the positive nitrogen ion in its structure. On dissolution, the oxalate ion enters the aqueous solution ensuring that the dye has an overall positive charge. The positive charge on the cationic dye should ensure that it is attracted by an anionic adsorbent.

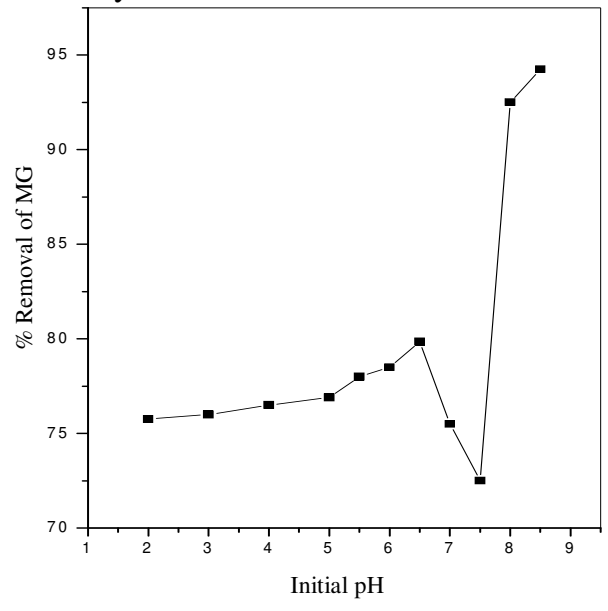

Figure 6. Effect of initial $\mathrm{pH}$ on the adsorption of malachite green onto $\mathrm{ZDC}[\mathrm{M} \mathrm{G}]=30$ $\mathrm{mg} / \mathrm{L}$; contact time $=60 \mathrm{~min}$; temp $30{ }^{\circ} \mathrm{C}$; adsorbent dose $=25 \mathrm{mg} / 50 \mathrm{~mL}$

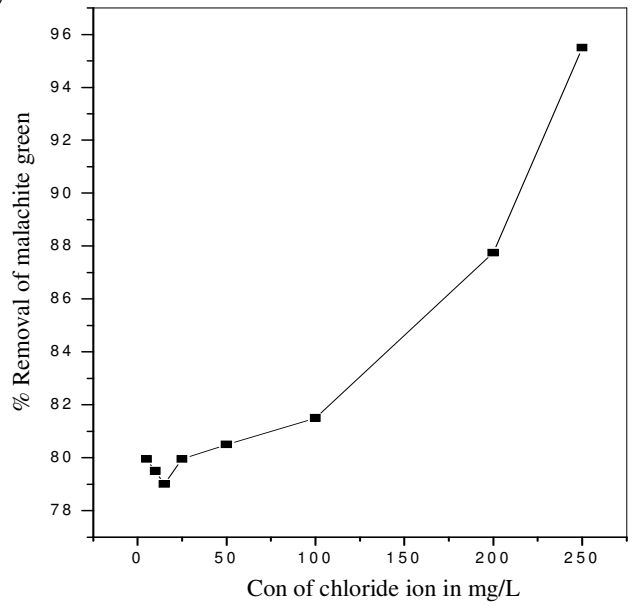

Figure 7. Effect of other ions on the adsorption of malachite green onto ZDC [M G] $30 \mathrm{mg} / \mathrm{L}$; adsorbent dose $=25 \mathrm{mg} / 50 \mathrm{~mL}$; Temp $30{ }^{\circ} \mathrm{C}$; contact time $60 \mathrm{~min}$

In carbon-aqueous systems the potential of the surface is determined by the activity of ions $\left(\right.$ e.g. $\mathrm{H}^{+}$and $\left.\mathrm{pH}\right)$, which react with the carbon surface. For the carbon surface the potential determining ions are $\mathrm{H}^{+}$and $\mathrm{OH}^{-}$and complex ions formed by bonding with $\mathrm{H}^{+}$and $\mathrm{OH}^{-}$. The broken bonds along the surface of the carbon result in hydrolysis.

At low $\mathrm{pH}$ the reaction might be:

\section{At high $p H$ the reaction is}

$$
\text { Carbon- } \mathrm{OH}+\mathrm{H}^{+} \rightarrow \text { Carbon- } \mathrm{OH}_{2}^{+}
$$

$$
\text { Carbon- } \mathrm{OH}+\mathrm{OH}^{-} \rightarrow \text { Carbon- }^{-}+\mathrm{H}_{2} \mathrm{O}
$$

In our studies the maximum adsorption is at $\mathrm{pH} 9.0$. So at high $\mathrm{pH}$, the solution in contact with the basal oxygen surface of the tetrahedral sheet will contain excess hydroxyls. The surface will then exhibit a cation exchange capacity ${ }^{15-17}$.

\section{Effect of the ionic strength on the adsorption of malachite green}

The effect of sodium chloride on the adsorption of malachite green on zea mays dust carbon is shown in Figure 7. In a low solution concentration $\mathrm{NaCl}$ had little influence on the adsorption capacity. At higher ionic strength the adsorption Malachite green will be increased due to the partial neutralization of the positive charge on the carbon surface and a consequent compression of the electrical double layer by the $\mathrm{Cl}^{-}$anion. The chloride ion can also enhances adsorption of malachite green ion onto zea mays dust carbon by pairing of their charges and hence reducing the repulsion between the malachite green molecules adsorbed on the surface. This initiates carbon to adsorb more of positive malachite green ions ${ }^{12,13,17,18}$. 


\section{Desorption studies}

Desorption studies help to elucidate the nature of adsorption and recycling of the spent adsorbent and the dye. The effect of various reagents used for desorption studies indicate that hydrochloric acid is a better reagent for desorption, because we could get more than $74 \%$ removal of adsorbed dye. The reversibility of adsorbed dye in mineral acid or base is in agreement with the $\mathrm{pH}$ dependent results obtained. The desorption of Malachite green dye by mineral acids medium indicates that the dyes were adsorbed onto the activated carbon through by physisorption mechanisms ${ }^{11,15,18}$.

\section{Conclusion}

zea mays dust has been available in different parts of the country. In the present study, zea mays dust carbon was selected as a local, cheaper and readily available adsorbent for the removal of malachite green oxalate from the aqueous solutions. Adsorption of the dye was studied by batch technique and it was observed that more than $84 \%$ of dye removal was achieved by using $0.025 \mathrm{~g}$ of zea mays dust carbon. The kinetics of adsorption developed can be used to achieve low levels of dye from aqueous solutions utilizing the chosen carbon. Almost $92 \%$ removal of dye was observed at $\mathrm{pH}$ of 9.0. The adsorption data seems to follow the Langmuir and Freundlich isotherms.

\section{References}

1. Arivoli S, Kinetic and thermodynamic studies on the adsorption of some metal ions and dyes onto low cost activated carbons, Ph D., Thesis, Gandhigram Rural University, Gandhigram, India, 2007.

2. Sekaran G, Shanmugasundaram K A, Mariappan M and Raghavan K V, Indian J Chem Technol, 1995, 2, 311.

3. Selvarani K, Studies on Low cost Adsorbents for the removal of organic and Inorganics from Water, Ph D., Thesis, Regional Engineering College, Thiruchirapalli, 2000.

4. Jia Y F and Thomas K K, Langmuir, 2002, 18, 470-478.

5. Namasivayam C, Muniasamy N, Gayathri K, Rani M and Renganathan K, Biores Technol, 1996, 57, 37.

6. Namasivayam C and Yamuna R T, Environ Pollut., 1995, 89(1), 1-7.

7. Langmuir I, J Am Chem Soc., 1918, 40, 1361.

8. Freundlich H, Phys Chemie., 1906, 57, 384-470.

9. Krishna D G and Bhattacharyya G, Appl Clay Sci., 2002, 20, 295.

10. Arivoli S, Viji Jain M and Rajachandrasekar T, Mater Sci Res India, 2006, 3, 241-250.

11. Arivoli S and Hema M, Int J Phys Sci., 2007, 2, 10-17.

12. Arivoli S, Venkatraman B R, Rajachandrasekar $\mathrm{T}$ and Hema M, Res J Chem Environ., 2007, 17, 70-78.

13. Arivoli S, Kalpana K, Sudha R and Rajachandrasekar T, E- J Chem., 2007, 4, 238-254.

14. Weber W J, Principle and Application of Water Chemistry, Edited by Faust S D and Hunter J V Wiley, New York, 1967.

15. Renmin Gong, Yingzhi Sun, Jian Chen, Huijun Liu and Chao yang, Dyes and Pigments, 2005, 67, 179.

16. Vadivelan V and Vasanthkumar K, J Colloid Interf Sci., 2005, 286, 91.

17. Yupeng Guo, Jingzhu Zhao, Hui Zhang, Shaofeng Yang, Zichen Wang and Hongding $\mathrm{Xu}$, Dyes and Pigments, 2005, 66, 123-128.

18. Sreedhar M K and Anirudhan T S, Indian J Environ Protect, 1999, 19, 8. 


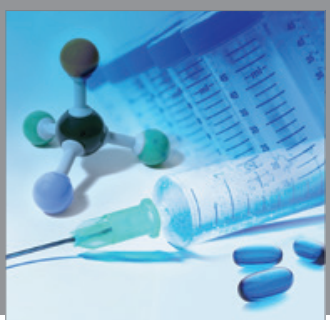

International Journal of

Medicinal Chemistry

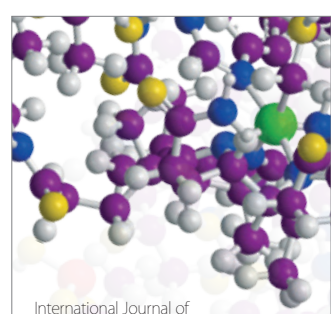

Carbohydrate Chemistry

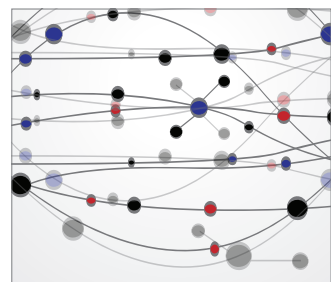

The Scientific World Journal
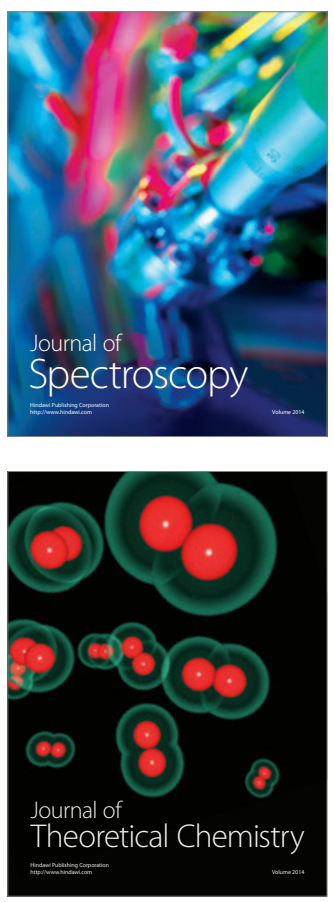
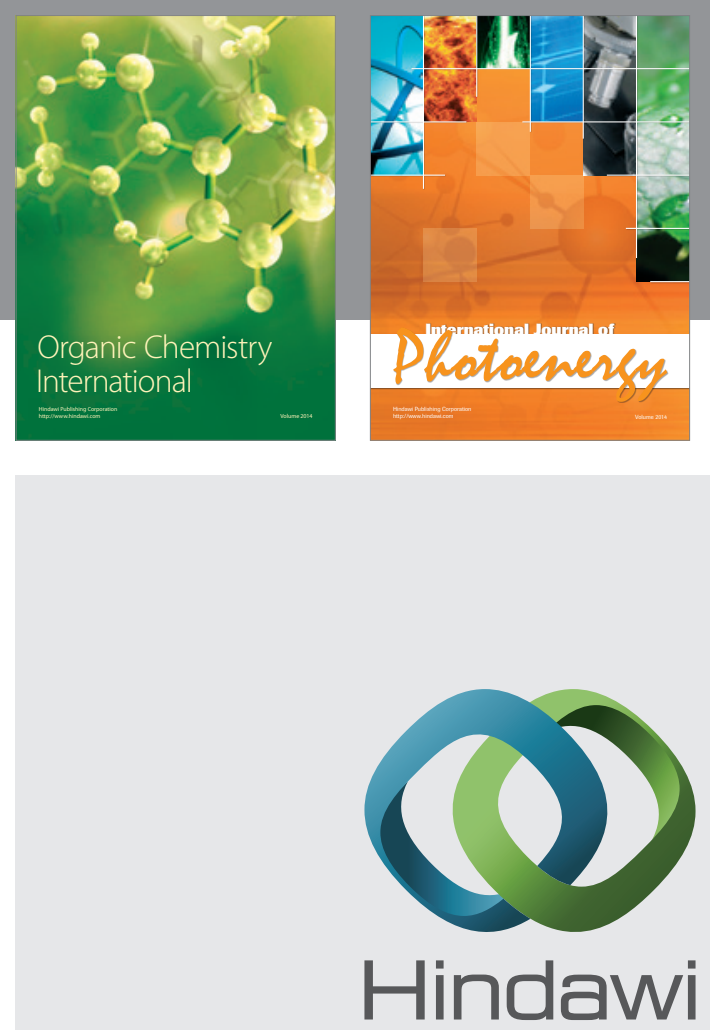

Submit your manuscripts at

http://www.hindawi.com
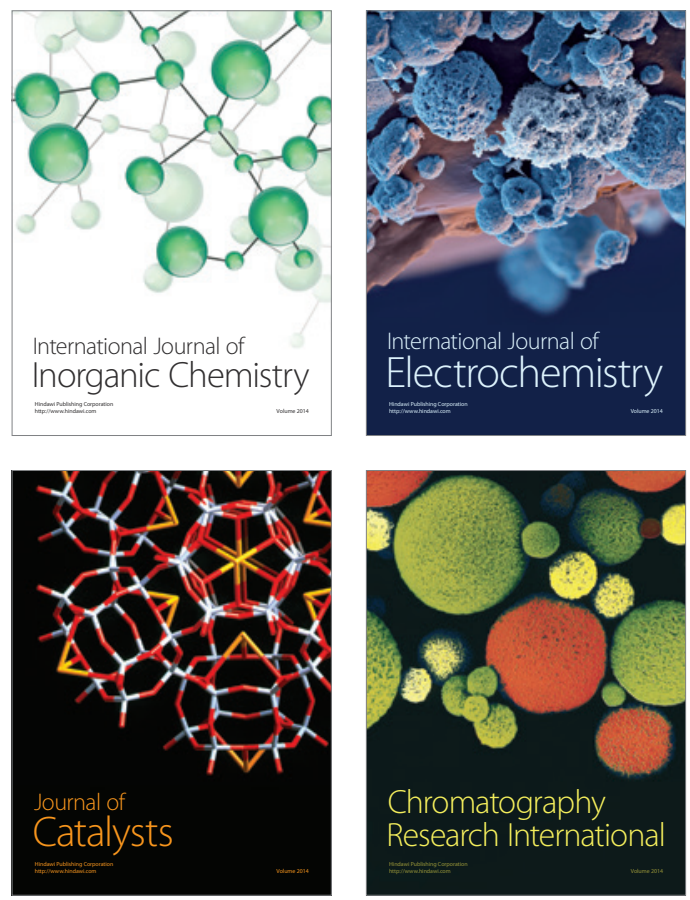
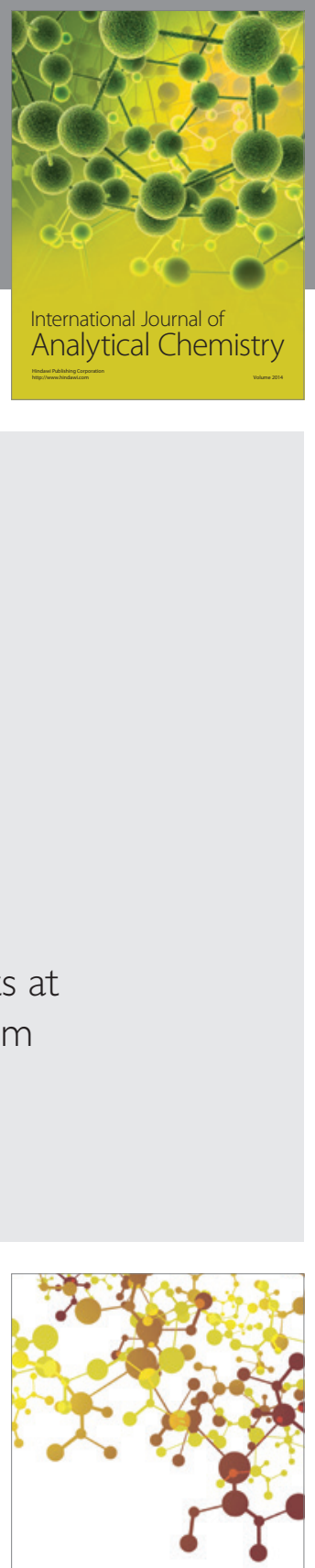

Journal of

Applied Chemistry
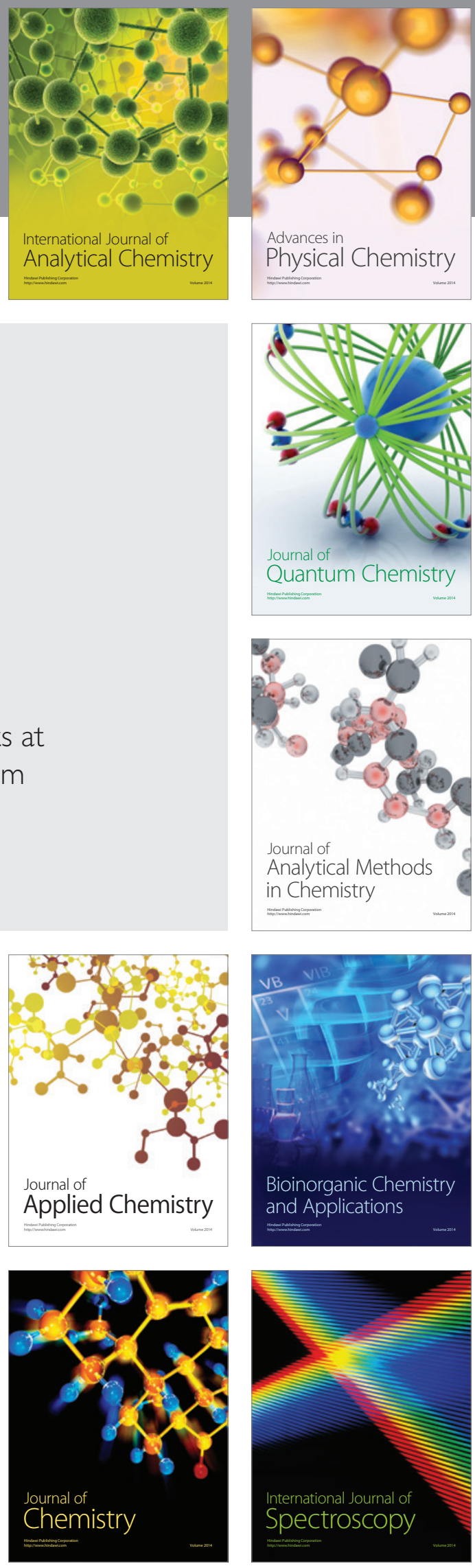